\title{
Performance Evaluation of a Throttleable Solid Propellant Thruster Using Laser Heating
}

\author{
By Shota IsAKARI, ${ }^{1)}$ Shingo OnIZUKA, ${ }^{1)}$ Yasuyuki YANO $^{2)}$ and Akira KAKAMI ${ }^{3)}$ \\ 1) Department of Mechanical Systems Engineering, University of Miyazaki, Miyazaki, Japan \\ ${ }^{2)}$ Faculty of Engineering, University of Miyazaki, Miyazaki, Japan \\ 3) Department of Mechanical Design Systems Engineering, University of Miyazaki, Miyazaki, Japan
}

(Received July 31st, 2015)

\begin{abstract}
This paper describes a solid propellant microthruster that is throttleable using laser heating. Solid propellant thrusters generally require neither tank nor valve, and accordingly have relatively high reliability due to simple structures. Nevertheless, conventional solid propellant thrusters have not been applied to attitude control or station keeping for satellites because of difficulty in throttling including start and interrupt of thrust production. Hence, we proposed to apply combustioncontrollable solid propellants, and a compact and light-weight semiconductor laser to thrusters in order to develop a throttleable solid propellant microthruster. For combustion controllable solid propellants, combustion was sustained only when external heat was supplied to burning surface. In our previous study, a prototyped $0.1 \mathrm{~N}$ class thruster successfully produced thrust in a vacuum, but the combustion was unstable. In this paper, to stabilize combustion, we prototyped a nozzle with a reduced target combustion chamber pressure of $0.03 \mathrm{MPa}$. Mass ratio of carbon black, which was added to absorb laser beam efficiently, was varied from $0.05 \mathrm{wt} \%$ to $0.5 \mathrm{wt} \%$. Thrust measurement showed that the prototyped thruster successfully yields a stable thrust of $0.02 \mathrm{~N}$ at a laser power density of $0.98 \mathrm{~W} / \mathrm{mm}^{2}$.
\end{abstract}

Key Words: Solid Propellant, Microthruster, Laser Heating, Throttling

\section{Nomenclature}

$r \quad$ : burning rate, $\mathrm{mm} / \mathrm{s}$

$L^{*} \quad$ : characteristic length of combustion chamber, $\mathrm{m}$

$v \quad:$ laser head traverse velocity, $\mathrm{mm} / \mathrm{s}$

$t \quad$ : time, $\mathrm{s}$

$P \quad$ : pressure, $\mathrm{MPa}$

$T \quad$ : thrust, $\mathrm{N}$

$I_{\mathrm{sp}} \quad$ : specific impulse, $\mathrm{s}$

Subscripts

c : combustion chamber

\section{Introduction}

Today, microsatellites are attracted because of lower development cost and shorter development period. While microthrusters are necessary for complex and precise mission by microsatellite, most microsatellites has no thruster, and accordingly are not able to conduct a complex mission. Therefore, a reliable high-performance microthruster is necessary to realize more aggressive missions. Hence, we focused on a solid propellant thruster, which is compact, reliable, and light weight among thrusters. Solid propellant thrusters have the following features; they require neither tank nor valve, which are indispensable to liquid propellant thrusters but increases system weight. Solid propellant is never leaked in the space. Conventional solid propellant thrusters, however, have never been applied to attitude control or station keeping for spacecraft because of difficulty in throttling including start and interrupt of thrust production.

In this study, we proposed to apply combustion-controllable solid propellants and compact and light-weight semiconductor lasers to thrusters in order to develop a throttleable solid propellant microthruster. For combustion controllable solid propellants, combustion is sustained only when external heat was supplied to the burning surface. Our previous study has shown that for Hydroxyl terminated poly butadiene (HTPB) / Ammonium perchlorate (AP) / Carbon black (C) = 30/70/0.5 $\mathrm{wt} \%$, combustion was controllable by switching laser. ${ }^{1)} \mathrm{A} 0.1$ $\mathrm{N}$ class prototyped microthruster with a target combustion chamber pressure of $0.1 \mathrm{MPa}$ successfully generated thrust during laser heating, and interrupted combustion by pausing laser irradiation. The thruster, however, yielded an unstable combustion; during laser irradiation, combustion was repeatedly started and intermitted. This would be attributed to a target chamber pressure ranging from 0.1 to $0.3 \mathrm{MPa}$. Strand burner tests showed that combustion was unstable in the vicinity of $0.18 \mathrm{MPa}^{2-3)}$

A thruster using a nozzle with a reduced target combustion chamber pressure of $0.03 \mathrm{MPa}$ was prototyped and tested in order to stabilize combustion and enhance performance. Figure 1 exhibits the dependence of burning rate on back pressure at the room temperature. At back pressures above $0.1 \mathrm{MPa}$, burning rate is decreased owing to unstable combustion. Therefore, we designed a nozzle of $0.03 \mathrm{MPa}$ in target thrust chamber pressure to stabilize combustion.

Mixture ratio of carbon black in solid propellant was varied from 0.05 to $0.5 \mathrm{wt} \%$ to investigate the dependence on performance, since carbon black assists combustion by absorb- 


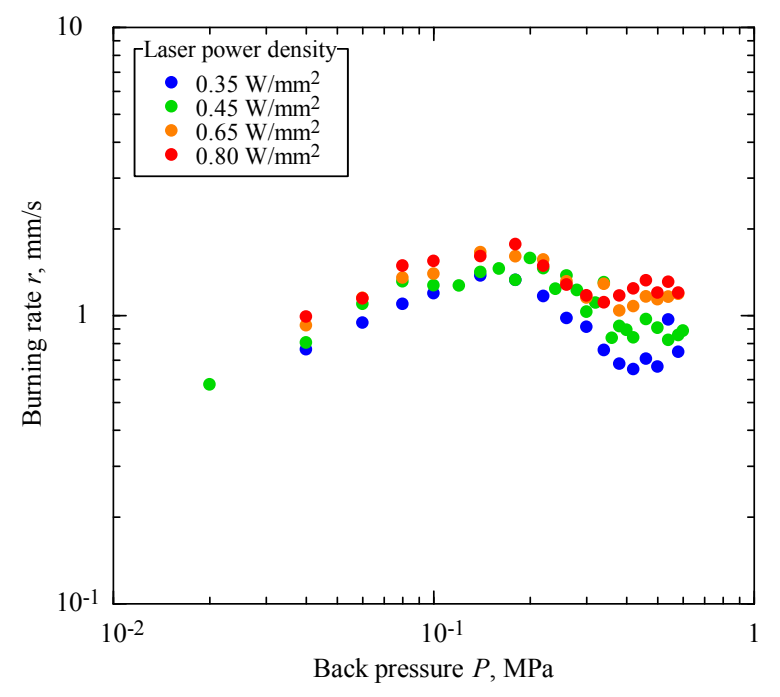

Fig. 1. Burning rate on back pressure for $\mathrm{HTPB} / \mathrm{AP} / \mathrm{C}=30 / 70 / 0.5 \mathrm{wt} \%$.

ing laser, but reduces theoretical specific impulse.

\section{Prototyped 0.1 N Class Microthruster}

Figure 2 shows a schematic diagram of the designed microthruster where combustion was started, and interrupted by adjusting laser heating on burning surface. A propellant holder, made of acryl, was a propellant container which effectively transmits laser beam. A laser head was moved with a linear traverser so that the burning surface, which was autonomously regressed by combustion, always kept heated with the laser.

\subsection{Nozzle}

Figure 3 illustrates a prototyped stainless-steel nozzle for the thruster, and Table 1 presents the configuration. The nozzle had a throat of $0.79 \mathrm{~mm}^{2}$ in cross section with an area ratio of 50, as to produce $0.1 \mathrm{~N}$ thrust in a vacuum. Characteristic length of combustion chamber $L^{*}$ was tentatively $3.0 \mathrm{~m}$. In HTPB/AP combustion, reaction zone is an order of micrometer, combustion process completes in the vicinity of the burning surface. ${ }^{4)}$ Moreover, an increase in $L^{*}$ enlarges heat loss, which deteriorates specific impulse. Although the thruster should have lower $L^{*}$, the prototype had the large $L^{*}$ to prepare a pressure sensor port. ${ }^{5)}$

\subsection{Solid propellant}

An HTPB/AP composite solid propellant was used because of high performance among solid propellants. Mixture ratio was summarized in Table 2. The propellant is the trimodal composite propellant, in which 10-, 200-, 400- $\mu$ m diameter AP particles are mixed at the same mass ratio. Our previous study showed that for $\mathrm{HTPB} / \mathrm{AP} / \mathrm{C}=30 / 70 / 0.5 \mathrm{wt} \%$, combustion was controllable below $0.58 \mathrm{MPa}$ by adjusting laser power. ${ }^{6} \mathrm{~A}$ propellant sample had a rectangular shape $5 \times 5 \times 20 \mathrm{~mm}^{3}$ in size, so that the upper surface of the propellant was heated with traveling laser spot of approximately $5 \mathrm{~mm}$ in diameter. Carbon black powders were added into the propellant at mass ratios of 0.5 and $0.05 \mathrm{wt} \%$ in order to effectively absorb near-infrared laser beam.

Theoretical specific impulse was calculated using a chemical equilibrium calculation program, Chemical Equilibrium with

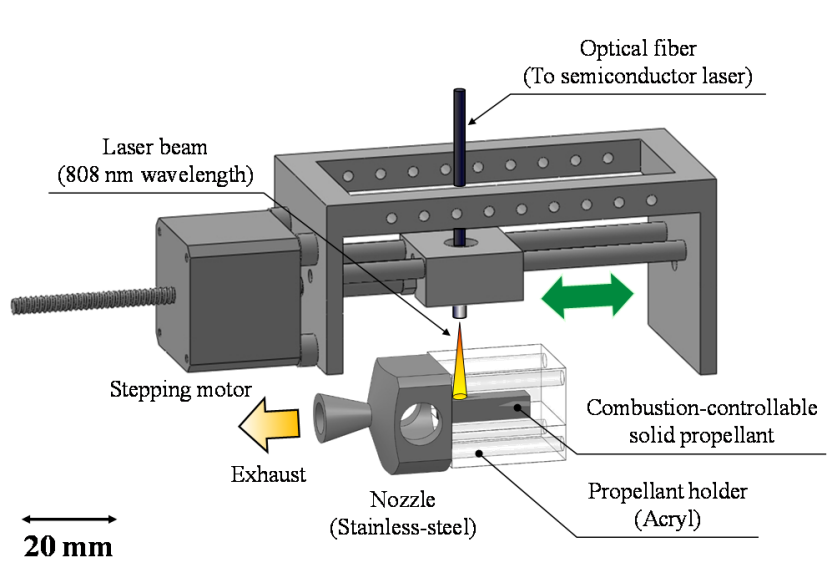

Fig. 2. Schematic diagram of a proposed microthruster.

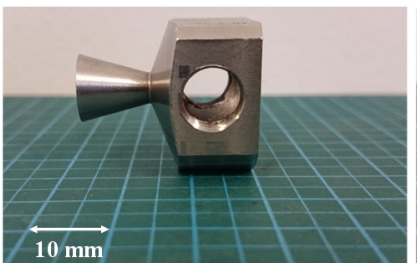

(a) Side view

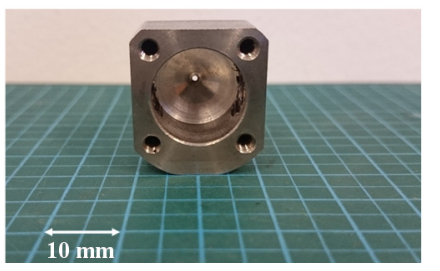

(b) Back view
Fig. 3. Prototyped nozzle.

Table 1. Configuration of prototyped nozzle.

\begin{tabular}{lc} 
Target thrust $T, \mathrm{~N}$ & 0.1 \\
Target combustion chamber pressure $P_{\mathrm{c}}, \mathrm{MPa}$ & 0.03 \\
Throat cross section $A_{\mathrm{t}}, \mathrm{mm}^{2}$ & 0.79 \\
Combustion chamber volume $V_{\mathrm{c}}, \mathrm{mm}^{3}$ & 2372.9 \\
Characteristic length $L^{*}, \mathrm{~m}$ & 3.0 \\
Nozzle area ratio $\varepsilon$ & 50 \\
\hline
\end{tabular}

Table 2. Mixture ratio of solid propellants.

\begin{tabular}{ccccc}
\hline \hline \multirow{2}{*}{$\begin{array}{c}\text { Propellant } \\
\text { No. }\end{array}$} & \multicolumn{3}{c}{ Mixture ratio, wt $\%$} & Theoretical \\
\cline { 2 - 4 } & HTPB & AP & C & $I_{\text {sp }}, \mathrm{s}$ \\
\hline 1 & 30 & 70 & 0.5 & 204.5 \\
2 & 30 & 70 & 0.05 & 207.1 \\
\hline \hline
\end{tabular}

Applications (CEA). ${ }^{7)}$ Propellant 1 had a theoretical specific impulse of $204.5 \mathrm{~s}$, and propellant 2 had $207.1 \mathrm{~s}$. Theoretical specific impulses were almost the same for propellants 1 and 2 .

\subsection{Linear traverser for laser head}

A laser head was moved with a linear traverser during laser heating. In combustion, the burning surface regressed with time, and accordingly the laser spot was required to keep up with the regressing burning surface to continuously heat the burning surface. A linear traverser, which was a screw-type linear traverser driven with a stepping motor, moved the laser head at velocities ranging from 0.3 to $0.6 \mathrm{~mm} / \mathrm{s}$.

\subsection{Semiconductor laser}

A 45-W class semiconductor laser of an $808 \mathrm{~nm}$ in wavelength (JOLD-45-CPXF-1L) was used as a heat source for sustaining combustion of solid propellant. Figure 4 shows a laser power profile at $13 \mathrm{~mm}$ from the laser head. Laser profile measurement yielded an average power density of $0.98 \mathrm{~W} / \mathrm{mm}^{2}$ with a laser-beam diameter of $5.65 \mathrm{~mm}$, which was slightly wider than the solid propellant of $5 \mathrm{~mm}$ in width. 


\section{Experimental Apparatus}

\subsection{Vacuum chamber}

The prototyped thruster, which is shown in Fig. 5, was tested in a cubic vacuum chamber of $320 \times 320 \times 320 \mathrm{~mm}^{3}$ in size. The vacuum chamber was made of stainless steel to prevent chemical damage due to combustion products. A vacuum pump evacuated the vacuum chamber, and reduced ambient pressure to $1.0 \mathrm{kPa}$.

\subsection{Thrust stand}

Thrust was measured with a thrust stand, which was fixed inside in the vacuum chamber. The thrust stand was a pendulum-type thrust measuring device, and thrust was determined from pendulum displacement, which was measured with a laser displacement sensor with $1.5-\mu \mathrm{m}$ resolution. An oil damper was used to attenuate pendulum oscillation that was induced by sudden change in thrust. The thrust stand was calibrated using a load cell.

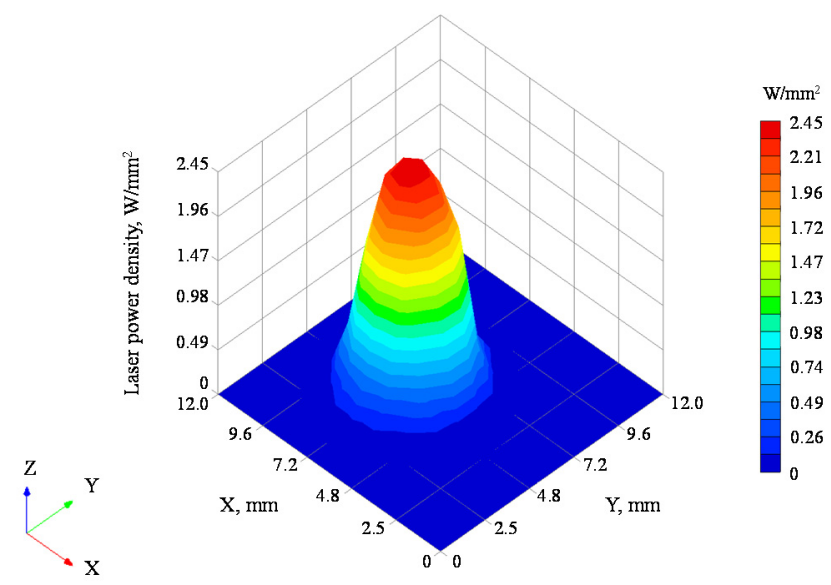

Fig. 4. Laser power profile.

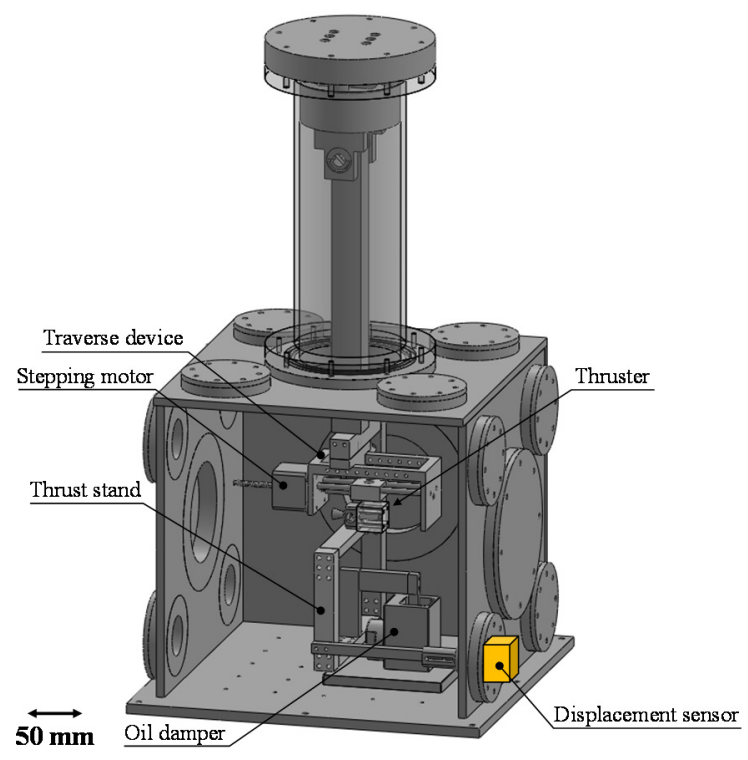

Fig. 5. Schematic of vacuum chamber with thrust stand.

\section{Experimental Procedure}

The prototyped thruster was placed on a thrust-stand arm, as shown in Fig. 5. The laser head was initially located above a nozzle-side end of the propellant holder. After laser heating was started, the laser head was moved with the linear traverser at velocities ranging from 0.3 to $0.6 \mathrm{~mm} / \mathrm{s}$. The traverse velocity was determined from burning rate, which was $0.5 \mathrm{~mm} / \mathrm{s}$ at 0.03 $\mathrm{MPa}{ }^{3)}$ When the laser head arrived in the vicinity of the other end of the rectangular propellant sample, laser heating was intermitted so that some part of propellant remained unburned. The unburned propellant at the opposing end of the nozzle was used as a proof of combustion control.

\section{Experimental Results and Discussion}

\subsection{Time history for stable combustion}

The prototyped thruster with propellant 1 successfully produced stable combustion during laser heating, as shown in Fig. 6. Figure 7 gives a typical time history for stable combustion, which was yielded at a laser head traverse velocity of $0.4 \mathrm{~mm} / \mathrm{s}$. Combustion was initiated at $3 \mathrm{~s}$ after the start of the laser irradiation. Whereas combustion was unstable for the first $10 \mathrm{~s}$ after ignition, the thruster subsequently showed almost constant combustion pressure. From this result, the thruster successfully yielded stable thrust because combustion was sustained without extinguishment or flickering. During stable combustion, the thruster presented an average combustion chamber pressure of $0.03 \mathrm{MPa}$, average thrust of $0.02 \mathrm{~N}, I_{\mathrm{sp}}$ of $95.3 \mathrm{~s}$, and $I_{\mathrm{sp}}$ efficiency of $46.6 \%$.

Pressure peaks at approximately 19 and 27 s would be attributed to non-uniform distribution of AP particles in solid propellant. In some points, AP particle would be locally agglomerated. When regressing burning surface arrives at an AP-agglomerated area, local burning rate would be suddenly incremented, and hence induces sudden rise in combustion chamber pressure. Moreover, the burning surface of the prototype is smaller than that of conventional solid rockets whereas the AP diameters were the same as those of conventional rockets. Hence, the prototype would readily induce large peak in combustion chamber pressure owing to AP agglomeration compared to the conventional solid rockets.

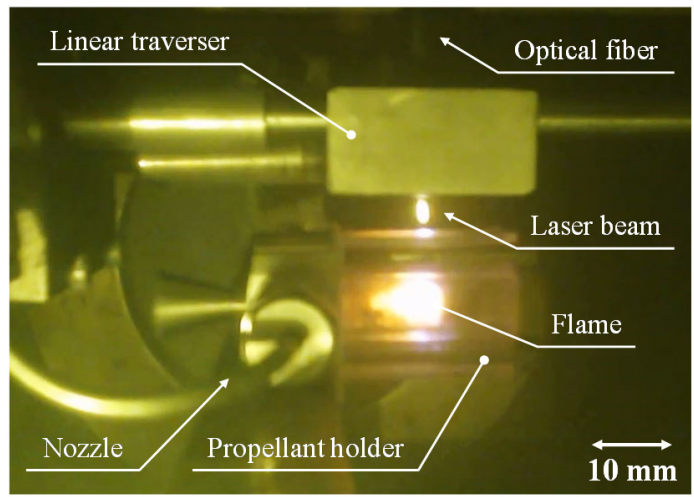

Fig. 6. Thruster firing at $v=0.4 \mathrm{~mm} / \mathrm{s}$, propellant with $0.5 \mathrm{wt} \%$. 


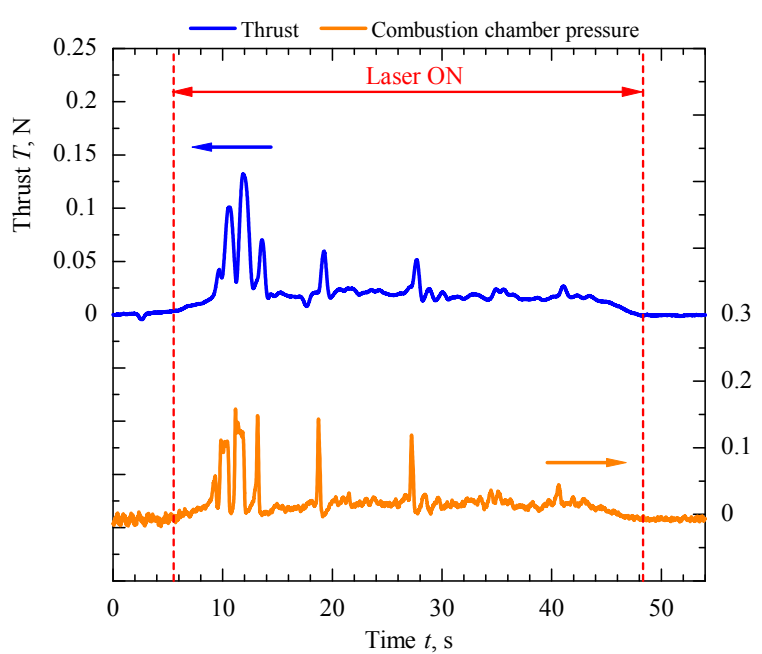

Fig. 7. Time history of combustion experiment for propellant 1 at laser head traverse velocity of $0.4 \mathrm{~mm} / \mathrm{s}$.

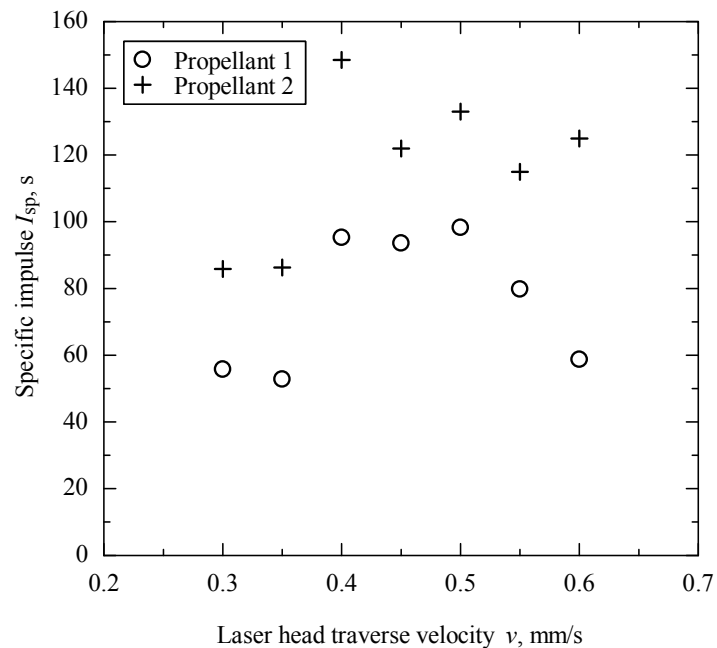

Fig. 9. Dependence of specific impulse on traverse velocity.

Table 3. Experimental results at $v=0.4 \mathrm{~mm} / \mathrm{s}$

\begin{tabular}{lcc}
\hline \hline & Propellant 1 & Propellant 2 \\
\hline Ignition delay, s & 3 & 5 \\
Average pressure $P_{\mathrm{c}}, \mathrm{MPa}$ & 0.03 & 0.04 \\
Average thrust $T, \mathrm{~N}$ & 0.02 & 0.03 \\
Specific impulse $I_{\mathrm{sp}}, \mathrm{s}$ & 95.3 & 148.5 \\
Specific impulse efficiency, \% & 46.6 & 71.7 \\
\hline \hline
\end{tabular}

\subsection{Time history for unstable combustion}

The thruster shows unstable combustion under some conditions. Figure 8 exhibits a typical time history for unstable combustion. In this case, propellant 2 was tested at the laser head traverse velocity of $0.4 \mathrm{~mm} / \mathrm{s}$. The thruster started to produce a thrust at $5 \mathrm{~s}$ after starting laser irradiation. Afterwards, combustion was repetitively started and interrupted during laser heating. The corresponding performance is summarized in Table 3 .

\subsection{Dependence of performance and stability on propellant}

Propellant 1 presented lower specific impulse than propellant 2 at all the laser head traverse velocities, as shown in Fig. 9; pr-

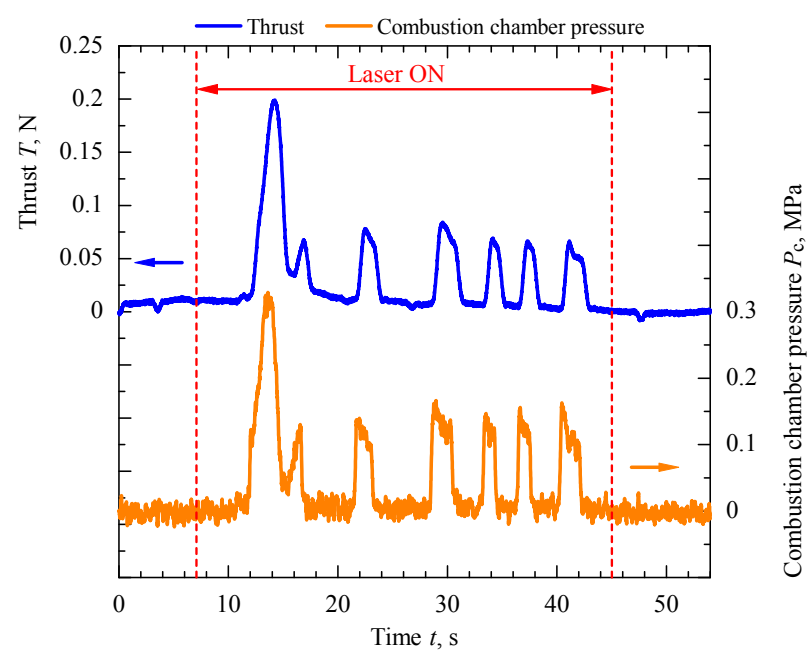

Fig. 8. Time history of combustion experiment for propellant 2 at laser head traverse velocity of $0.4 \mathrm{~mm} / \mathrm{s}$.

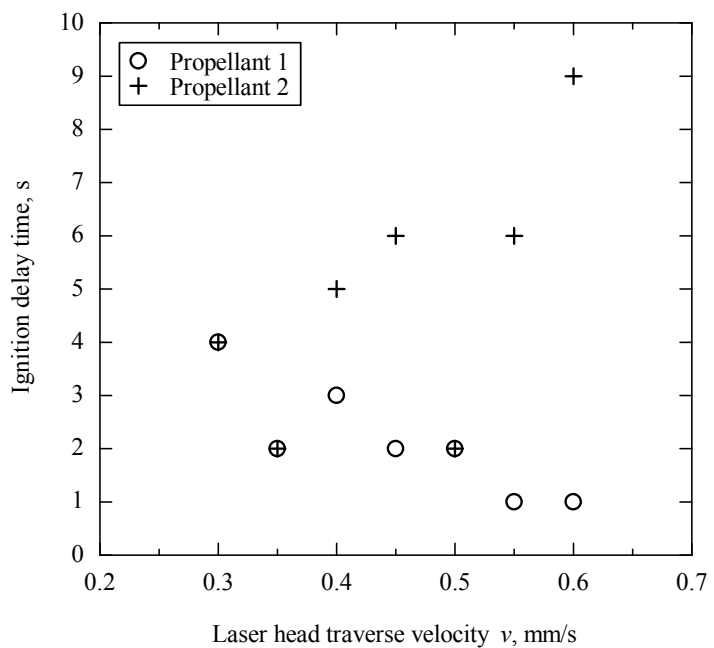

Fig. 10. Dependence of ignition delay time on traverse velocity.

Table 4. Stability in thrust production.

\begin{tabular}{cccccccc}
\hline \hline Propellant & \multicolumn{7}{c}{ Laser head traverse velocity $v, \mathrm{~mm} / \mathrm{s}$} \\
\cline { 2 - 7 } No. & 0.3 & 0.35 & 0.4 & 0.45 & 0.5 & 0.55 & 0.6 \\
\hline 1 & $\triangle$ & $\triangle$ & $\bigcirc$ & $\bigcirc$ & $\bigcirc$ & $\bigcirc$ & $\triangle$ \\
2 & $\triangle$ & $\triangle$ & $\triangle$ & $\triangle$ & $\triangle$ & $\triangle$ & $\triangle$ \\
\hline \hline
\end{tabular}

$\bigcirc$ : Stable thrust production, $\triangle$ : Unstable thrust production

opellant 1 showed a maximum $I_{\mathrm{sp}}$ of $98.3 \mathrm{~s}$ while propellant 2 yielded $148.5 \mathrm{~s}$. Nevertheless, propellant 1 yielded shorter ignition delay than propellant 2, as illustrated in Fig. 10. Moreover, propellant 1 presented stable combustion at laser head traverse velocity ranging from 0.4 to $0.55 \mathrm{~mm} / \mathrm{s}$, whereas propellant 2 yielded unstable combustion for all the laser head traverse velocities, as shown in Table 4. From these results, propellant 1 presented shorter ignition delay, stable combustion with lower specific impulse, whereas propellant 2 longer ignition delay and unstable combustion with higher specific impulse.

Specific impulse was lower than the theoretical value. This would be because the prototype did not reach thermal equilibrium owing to short burning period of approximately 20 
s. Moreover, pressure measurement of combustion chamber required the prototype to have an excessive $L^{*}$ of $3.0 \mathrm{~m}$, which is larger than the value that is necessary to complete combustion. The larger combustion chamber would enlarge heat loss and time for reaching thermal equilibrium. Hence, reduced $L^{*}$ and longer period for thruster firing would enhance specific impulse.

\subsection{Ignition delay}

Ignition delay is attributed to laser absorbance and low pressure at ignition. HTPB and AP reflects some near infrared laser beam, whereas carbon black effectively absorbs it. Hence, increase in ratio of carbon black would reduce ignition delay. Smaller-diameter carbon black powders may reduce ignition delay. In general, reducing diameter increases surface-tovolume ratio. Hence, use of fine carbon black powder would reduce the thickness required to absorb laser beam, enhance local temperature in laser-irradiated area, and reduce ignition delay.

Combustion-chamber pressure at ignition also induced ignition delay. The strand burner test showed that ignition with a delay of less than $1 \mathrm{~s}$ required approximately $10-\mathrm{kPa}$ back pressure. ${ }^{8)}$ Nevertheless, the combustion chamber pressure at ignition was approximately $1 \mathrm{kPa}$, which was the vacuum chamber pressure because solid propellant was not completely adhered to the acryl propellant holder. For the current prototype, longer-period laser heating is necessary to evaporate propellant and its holder as to raise pressure neighboring laser-heated propellant surface. Hence, improvement in propellant adhesion to acryl would reduce ignition delay.

\subsection{Cause of unstable combustion}

As previously mentioned, propellant 1 showed stable combustion at traverse velocities ranging from 0.4 to $0.55 \mathrm{~mm} / \mathrm{s}$, which were approximately equal to burning rate. From these results, the dependence on the laser head traverse velocity can be explained as follows. When the laser head traverse velocity approximately equals burning rate, the laser head can follow regressing burning surface. Hence, burning surface is continuously kept heated, and this leads to stable thrust production. Nevertheless, when the traverse velocity is much slower than the burning rate, the laser-preheated area of prope-

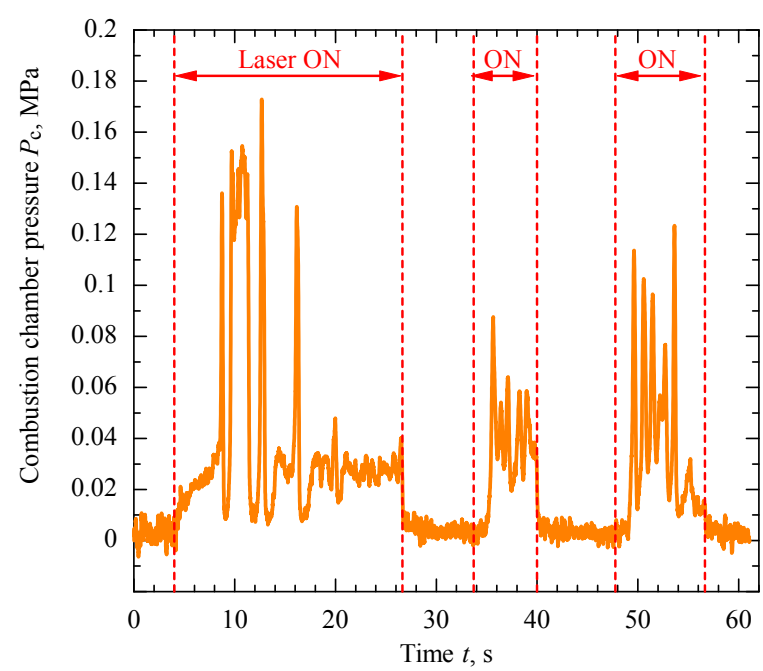

Fig. 11. Time history of combustion chamber pressure: restarting combustion test. llant is burned out before the laser head moves to the unburned area. Then, combustion is interrupted owing to the lack of propellant in the laser irradiated area. After the laser head arrives above the unburned propellant, solid propellant is reignited with a latency. This process is repeated during laser heating.

In case the traverse velocity is faster than burning rate, the laser head moves to neighboring non-heated area before igniting already-heated areas. After the preheated area is suddenly ignited, it immediately burns out because heated solid propellant generally yields higher burning rate. Then, the traveling laser head heats the unheated area, which would be ignited later. From the consideration, the discrepancy between burning rate and traverse velocity possibly induces repetitive ignition and quenching.

\subsection{Reignition test}

Reignition test was conducted to show that the proposed thruster was able to start, interrupt and restart combustion by switching laser. Figure 11 shows a time history in combustion chamber pressure for propellant 1 at a laser head traverse velocity of $0.4 \mathrm{~mm} / \mathrm{s}$. Combustion was started at $t=4 \mathrm{~s}$ and interrupted by switching laser heating at $t=26 \mathrm{~s}$. Then, the thruster was restarted by restarting laser heating, and then interrupted again by stopping laser heating. From this result, the thruster successfully started, interrupted and restarted combustion simply by adjusting laser.

\section{Summary}

The followings are summary of this paper.

1. We proposed a throttleable solid propellant thruster using laser heating and combustion controllable solid propellant, in which combustion was sustained only when burning surface is heated.

2. Carbon black were added into HTPB/AP propellant at mass ratio 0.05 and $0.5 \mathrm{wt} \%$ in order to absorb nearinfrared laser beam.

3. Propellant 1 , which contains $0.5 \mathrm{wt} \%$ carbon black, presented a stable thrust and combustion chamber pressure. At laser head traverse velocity $0.5 \mathrm{~mm} / \mathrm{s}$, average combustion chamber pressure of $0.04 \mathrm{MPa}$, average thrust of $0.02 \mathrm{~N}$, and $I_{\mathrm{sp}}$ was $98.3 \mathrm{~s}$.

4. Stability in thrust production was affected by mixture ratio of carbon black and traverse velocity. Propellant 1 exhibited stable thrust production at laser head traverse velocity ranging from 0.4 to $0.55 \mathrm{~mm} / \mathrm{s}$, whereas propellant 2 yielded unstable thrust production at all the tested laser-head traverse velocities.

5. Propellant 2, which contains $0.05 \mathrm{wt} \%$ carbon black, showed higher specific impulse than propellant 1 at any laser head traverse velocity. Propellant 2 shows, $I_{\mathrm{sp}}$ of $148.5 \mathrm{~s}$, and $I_{\mathrm{sp}}$ efficiency of $71.7 \%$ at $0.4 \mathrm{~mm} / \mathrm{s}$.

6. The reason propellant 1 showed stable combustion at 0.4 to $0.55 \mathrm{~mm} / \mathrm{s}$ was that the velocity was approximately equal to burning rate.

7. Reignition test showed that the prototyped thruster successfully started, interrupted and restarted combustion simply by adjusting laser. 


\section{Acknowledgments}

This work was supported by JSPS KAKENHI Grant Number 25289308 (Grant-in-Aid for Scientific Research (B)).

\section{References}

1) Kakami, A., Terashita, S. and Tachibana, T.: A Laser Heating Method for Estimating Thermal Balance of Burning Solid Propellants, Science and Technology of Energetic Materials, 70, No.6 (2009), pp.145-151.

2) Kakami, A., Hamada, T., Shimoda, M. and Tachibana, T.: Throttleable solid propellant microthruster using laser-assisted combustion, 49th AIAA/ASME/SAE/ASEE Joint Propulsion Conference \& Exhibit, San Jose, California, AIAA-2013-4078, 2013.

3) Kakami, A., Terashita, S. and Tachibana, T.: Application of laserassisted combustion to solid propellant for space propulsion, 46th AIAA/ASME/SAE/ASEE Joint Propulsion Conference \& Exhibit, Nashville, Tennessee, USA, AIAA-2010-6584, 2010.
4) Kubota, N.: Propellants and Explosives, WILEY-VCH GmbH, Weinheim, Germany, 2007, pp.79-82.

5) Onizuka, S., Isakari, S., Yano, Y. and Kakami, A.: Throttlable solid propellant thruster using laser heating, Space Transportation Symposium FY2014, STCP-2014-031, Sagamiahra, Japan, 2015 (in Japanese).

6) Hamada, T., Shimoda, M., Kakami, A. and Tachibana, T.: A Lasercontrolled Micro Solid Propellant Thruster, Space Transportation Symposium FY2012, STCP-2012-006, Sagamiahra, Japan, 2013 (in Japanese).

7) Gordon, S. and McBride, B. J.: Computer Program for Calculation of Complex Chemical Equilibrium Compositions and Applications, NASA Reference Publication 1311, 1996.

8) Kakami, A., Hiyamizu, R., Shuzenji, K. and Tachibana, T.: LaserAssisted Combustion of Solid Propellant at Low Pressure, Journal of Propulsion and Power, 24, No.6 (2008), pp.1355-1360. 